\title{
Access to healthcare system of indigenous communities with musculoskeletal disorders and rheumatic disease in Chaco, Argentina: a qualitative study
}

\author{
Rosana Quintana ${ }^{1}$ (D) - Sofia Fernandez ${ }^{2} \cdot$ Martina Fay $^{2} \cdot$ Cecilia Camacho $^{2} \cdot$ Graciela Gomez $^{2} \cdot$ Jazmin Petrelli $^{2}$. \\ Andrés Honeri $^{2}$ - Viviana Arenas Solórzano ${ }^{2}$ - Ana Bensi ${ }^{2} \cdot$ Gustavo Di Prinzio $^{2}$. Adriana Silvestre ${ }^{1}$. \\ Maria Elena Calvo $^{3} \cdot$ Ingris Pelaez-Ballestas $^{4} \cdot$ Marcela Valdata $^{2} \cdot$ Bernardo A. Pons-Estel $^{1}$
}

Received: 23 September 2020 / Revised: 30 October 2020 / Accepted: 15 November 2020 / Published online: 24 November 2020

(C) International League of Associations for Rheumatology (ILAR) 2020

\begin{abstract}
Key Points

- The different barriers between the community and the healthcare system were described.

- The "navigation" within the health system carried out by the qom

community and the migration were relevant points.

- The bureaucratization of the health system and the need to design and implement educational strategies in the future were highlighted.
\end{abstract}

Introduction/objectives The objective of this study is to describe the local healthcare system from the perspective of the health professionals, community health workers, and local representatives of the qom community living in the province of Chaco, Argentina. Methods A qualitative study, with an ethnographic approach, was carried out using two techniques: non-participant observations and semi-structured interviews. A guide for the interviews was designed and developed by a multidisciplinary group of GLADERPO researchers. The main aspects included were the following: reference into the local healthcare system and accessibility to the system. Andersen's base conceptual model of health service utilization was applied for the analysis and for structuring the results.

Results A total of 21 people were interviewed, twelve women and nine men with an age ranging between 25 and 60 years old. The main findings were different barriers (communication and cultural) between the community and the healthcare system; "navigation" within the health system carried out by the qom community; and migration and bureaucratization of the health system.

Conclusions These findings should be incorporated into educational strategies to improve access to healthcare system and adherence to medical treatment, establishing an interaction between the different levels of the local care system and providing community health workers with an appropriate training with the support of the community representatives.

Keywords Models of healthcare $\cdot$ Multidisciplinary approach $\cdot$ qom population $\cdot$ Qualitative methods

Rosana Quintana

rosanaquintana@gmail.com

1 Centro Regional de Enfermedades Autoinmunes y Reumáticas (GO-CREAR), Bv. Oroño 1024, Rosario, Santa Fe, Argentina

2 CEAPROS (Centro de Estudios Aplicados a Problemáticas Socio-culturales), Facultad de Humanidades y Artes, Universidad Nacional de Rosario (UNR), Rosario, Argentina

3 Hospital 4 de junio "Dr. Ramón Carrillo”, Presidencia Roque Saenz Peña, Chaco, Argentina

4 Hospital General de México "Dr. Eduardo Liceaga", Mexico, Mexico

\section{Introduction}

Rheumatic diseases, and specially rheumatoid arthritis (RA), represent chronic diseases which impact the quality of life and functionality of patients [1]. The global distribution of these diseases varies among the populations studied and is more prevalent in indigenous groups [2-4]. The Latin American Group for the Study of Rheumatic Diseases in Original Populations (GLADERPO) has been working with the qom population in Rosario City, province of Santa Fe, Argentina, and has shown a high prevalence of RA in this population [5].

The RA in the qom community is characterized as an aggressive disease, with poor adherence to clinical follow-up 
and treatment due to a migration pattern of moving from their hometown (province of Chaco) to urban areas [6]. GLADERPO's purpose is to build a network between the qom communities and the healthcare systems from the province of Chaco and the city of Rosario, allowing this migrant population to have access to healthcare regardless of their location and to improve adherence to medical treatment.

In other countries as Canada, Australia, and New Zealand, the impact of rheumatic disease in indigenous populations was also studied, showing differences in the access to healthcare [4].

Since official information on the healthcare system in Chaco is not available, GLADERPO decided to perform this qualitative study with the objective of describing the local healthcare system from the perspective of the health professionals, community health workers, and local representatives of the qom community. The group also aimed at describing community barriers, enablers, and needs and also making proposals to improve the access to the healthcare system of the qom population living in the province of Chaco, Argentina.

\section{Materials and methods}

\section{Design}

This qualitative research study, with an ethnographic approach, was carried out using two techniques: nonparticipant observations and semi-structured interviews. A guide for the interviews was designed and developed by a multidisciplinary group of GLADERPO researchers. The main topics included were the following: reference into the local healthcare system and accessibility (Annex 1).

Andersen's base conceptual model of health service utilization was applied [7, 8] for the analysis and for structuring the results. This model proposed three major factors that affected the access to health services: predisposing factors (demographic, social, economic, and cultural factors); enabling resources that influenced health service utilization, such as social relationships, community, and healthcare system characteristics; and needs, as perceived by the different actors. This framework was considered by the authors to be suitable for exploring the barriers and enablers in the access to the healthcare system by the qom community.

\section{Setting and participants}

The study was conducted in the city of Presidencia Roque Saenz Peña, located 1,077 km north of the capital city of Argentina and $744 \mathrm{~km}$ of Rosario City, with a population of more than 89,882 , being the second most populous city in the province of Chaco [9] (Fig. 1). There are 41,304 indigenous people living in Chaco, representing a $3.9 \%$ of the total province population. A $74.5 \%$
Fig. 1 Map with the cities involved in this study and distance to the capital city of Argentina

recognized themselves as belonging to the qom, $11.2 \%$ to the Wichi, and $9.4 \%$ to the Mocovi population [10]. The local indigenous population is organized into 14 communities, out of which only seven are recognized and identified as native by the local authorities. Demographic data of such communities is scarce and could only be partially retrieved from four of the seven recognized communities within the area: "Na'ala," "Paulo VI," "Santa Monica," and "Nam qom." The indigenous population is mostly composed of inhabitants of the qom community, with some inhabitants currently being married to Mocovies and Wichi ethnicities. These communities live under precarious conditions with the lack of essential services such as tap water, sewers, paving, or public transport.

The local healthcare system is currently made up of primary care centers (PACs), located in the neighborhoods, one very close to the other, and of a second-level hospital. Each PAC has a General Director, a nurse, a social worker, and community health workers. The two centers selected for this work were those with the highest number of qom population. PAC-1 reported, at the time of the study, a population of 3,005 inhabitants. Five hundred of them were indigenous inhabitants, and it was calculated that around 30 out of the 500 suffered from a rheumatic disease. CAP-2 reported a lower population, 1,418 inhabitants, composed of 230 families. The local hospital has specialized consultations, general 
hospitalization areas, and a critical care unit and provides attention to the city in addition to the nearby towns.

Since 2011, the Indigenous Health Care and Guidance Service (SASOI, by its acronym in Spanish) has been working within the hospital; its purpose is to guide, advise, and support, within the public healthcare system, indigenous patients and their families, ensuring service quality [11]. In this article, the term "community health workers" has been used for both: workers in the primary care setting (PAC community health workers) and workers in the hospital in the SASOI service (hospital community health workers). Both groups work independently. The administrative management of the PACs and the hospital is different.

Participants were purposely selected by researchers and invited to participate in advance. The inclusion criteria were health workers who were directly involved in providing healthcare services to qom community and who were willing to participate into the study.

The participants were local representatives of the qom community, healthcare professionals in the PACs (physicians, nurses, a social worker) and at the local hospital (a rheumatologist and two internists), and community health workers in the PACs and at the hospital. The representative of the qom community is elected by all the members of the community and it is him the only one who represents them before the provincial government.

\section{Data collection}

The data collection of this study involved individual and group interviews with local representatives of the qom community, healthcare professionals, and community health workers. Three of them were interviewed online due to preventive measures in Argentina during the SARS-CoV2 pandemic. All the interviews were conducted in Spanish, by the authors. The duration of the interviews ranged between 30 and $90 \mathrm{~min}$

\section{Data analysis}

All interviews were audio recorded and transcribed verbatim. Thematic data analysis was used to organize, classify, and guide interpretation. The research team was composed of individuals from different disciplines (anthropology and biomedicine) and all the authors participated in the phases of design, collection, analysis, and discussion of the results. A thematic analysis was carried out to identify the barriers [12, 13], enablers, and possible solutions to the socioeconomic and cultural challenges, as proposed by Andersen et al [7]. Coding was performed manually by two research team members (AH, CC, GDP, MV, GG, JP, MF, LG, SF). Another research team (MV, IPB, RQ) independently coded a subset of the data to check for convergence and consistency. A non-participant observation was performed by research team members $(\mathrm{AH}$, $\mathrm{CC}, \mathrm{GDP})$ at the same time of the semi-structured interviews. Each coder read and reread the transcripts several times. Analysis continued throughout the writing process. A triangulation strategy was implemented for the analysis: data triangulation and triangulation of researchers [14].. The consolidated criteria for reporting qualitative research (COREQ) were used by the authors as a checklist [15].

\section{Ethical considerations}

This study was approved by the Ethics Committee of Hospital 4 de Junio "Dr. Ramon Carrillo" register number 0026/19. The free, prior, informed consent to perform the study was provided by the local qom community representatives [16]. In addition, each participant orally provided their informed consent for participation into the study and this process was recorded.

\section{Results}

A total of 21 people was interviewed, twelve women and nine men with an age range between 25 and 60 years old. The distribution of the participants was the following: one local representative of the qom community and twenty, nine healthcare professionals (six working in PACs and three at the local hospital) and eleven community health workers (seven working in PACs and four at the local hospital), who currently provide medical care to the indigenous population. The group of healthcare professionals was formed by three nurses, five physicians, and one social worker.

The community health workers are given a grant by an indigenous health program. Although, officially, their activity is restrained to 6-h shifts from Monday to Friday, they are usually available $24 \mathrm{~h}$ a day in case of emergencies and other related events. Their daily shifts are distributed between morning duties in the PACs and afternoon rounds between the communities. Sometimes, they have to work full time. The role of the SASOI is to facilitate, translate, accompany, and administrate medical attention to the indigenous population within the hospital and, coordinated with the community health workers in the PACs, perform most of the daily duties within the 6-h shifts that they work from Monday to Friday. If necessary, they may work overtime to see a patient. The group is formed by 39 individuals who receive a grant by the government.

In this work, common findings are presented in an analogous model to the Andersen model about barriers (predisposing), enablers, and needs to healthcare attention to indigenous population, from the perspective of local representatives of the qom community, healthcare professionals (PACs and local hospital), and community health workers (PACs and local hospital) (Table 1). 
Table 1 Main findings based on Andersen model from different perspectives

\begin{tabular}{|c|c|c|c|c|}
\hline & From perspectives & qom community & PACs & Local hospital \\
\hline \multirow[t]{3}{*}{$\begin{array}{l}\text { Factors } \\
\quad \text { analyzed }\end{array}$} & $\begin{array}{l}\text { Barriers } \\
\quad \text { (predisposing) }\end{array}$ & $\begin{array}{l}\text { - Resistance and lack of } \\
\text { understanding of the local health } \\
\text { care system } \\
\text { - Lack of economic resources }\end{array}$ & $\begin{array}{l}\text { - Economic barriers } \\
\text { - Lack of coordination with the local hospital } \\
\text { - No official attention circuit } \\
\text { - Lack of specialized consultation }\end{array}$ & $\begin{array}{l}\text { - Lack of communication } \\
\text { between the hospital and the } \\
\text { PACs } \\
\text { - Bureaucratization of the } \\
\text { healthcare system } \\
\text { - Lack of specialized } \\
\text { consultation }\end{array}$ \\
\hline & Enablers & $\begin{array}{l}\text { - Knowledge of biomedical and } \\
\text { traditional medicine } \\
\text { - Role of "older people" }\end{array}$ & $\begin{array}{l}\text { - Compromise from healthcare professionals } \\
\text { - Teamwork }\end{array}$ & $\begin{array}{l}\text {-Roles of community health } \\
\text { workers } \\
\text { - Teamwork }\end{array}$ \\
\hline & Needs & $\begin{array}{l}\text { - Knowledge of healthcare system } \\
\text { - Improvement in the relationship } \\
\text { with the community health } \\
\text { workers }\end{array}$ & $\begin{array}{l}\text { - Development of culturally sensitive } \\
\text { competence } \\
\text { - Development of biomedical competence for } \\
\text { the early detection of rheumatic diseases }\end{array}$ & $\begin{array}{l}\text { - Training of community health } \\
\text { workers }\end{array}$ \\
\hline
\end{tabular}

\section{Barriers (predisposing factors): structural demographic, social, Economic, and cultural aspects}

The perspective of local representatives of the qom community There is resistance towards the biomedical system and lack of knowledge of the local healthcare system, the indigenous community do not know the health system and where to go when they are faced with pain, and there is lack of economic resources to cover diagnostic studies or treatments:

"we are very reluctant, we don't go to the doctor, sometimes we stop treatments" (a local representative of the qom community)

The dynamics of mobility between Rosario and Chaco are unknown:

"...go to Rosario brought about good and bad things.... The good ones: health and work... and the bad ones..." (a local representative of the qom community)

In relation to "bad things," he refers to the illicit drug young users in urban contexts.

The qom community is grateful to the other but it is also tired:

"an Indian is recognized from the distance, you can change your language, your clothes, your thoughts, but you cannot change your skin. Seeing a white man to be interested in indigenous peoples is of value to me, but our ancestors also saw many white people who didn't want to help them. There is pain from the ancestors." (a local representative of the qom community)

The perspective of healthcare professionals There are different points of view between PAC and hospital professionals; in the PACs, the main barriers are economic and lack of coordination with the local hospital. Patients do not know the way to navigate through the local healthcare system. There is no official attention circuit between the PACs and the hospital. However, "favors" between colleagues are the form of patient referral. Another issue is the lack of specialized consultation at the PACs. The patient is responsible for seeking specialized healthcare, by themselves, at the hospital:

"...people from the community arrive, maybe, when the patient cannot walk anymore because he is very painful." (a nurse with 20 years of experience at a PAC)

The role of community health workers is important; however, it is discontinued due to different factors. Their work is irregular and informal with small economic remuneration:

"...the work of PAC community health workers..., I have always told you, should be to detect a patient before his disease gets worse..." (a nurse with 20 years of experience at a PAC)

“...Yes, they are automatic renewable agreements... not automatic... because sometimes 2 or 3 months pass and they are not renewed... with the promise to be hired as a permanent employee." (the rheumatologist from the local hospital)

The physicians from the hospital observed that patients come alone and there is no formal channel of communication with the health center. It depends on individual relationships for referral and patient's follow-up:

"...I don't know if they have high tolerance to pain... we have a saying in the service: "when a Toba [popular name for qom] visits the doctor it is because he's really 
ill, you have to pay attention to him'... but they lack all this, all of the most important of the primary care, of getting faster to the health system." (an internist from the local hospital)

The role of community health workers into the hospital (SASOI) has been relevant to improve communication between patients, patients' families, and physicians. However, their work is not continuous due to government budget problems. Besides, there is no link between community hospital workers and the PACs.

"...before, we worked very little with them [SASOI] maybe their special way of being, we did not reach out to them, nor did them... since two or three years we have taken advantage from them, they get medicines for them, [patients] they get involved and bring them [patients] here, recently, they have been working very well." (an internist from the local hospital)

In the same way, the communication between the hospital and the PACs is neither fluid nor dynamic:

"(...) Here in Chaco, generally, we have a hospital and health areas. A health area groups all the health care centers. I'm not in a health area, I'm in a hospital...

"...what happens is that I cannot do anything of the health area [she refers to the PACs,] and they cannot do anything of the hospital" (the rheumatologist from the local hospital)

The bureaucratization of the health system is evident. The health teams work independently, and the care circuits from the first to the second level and vice versa are unknown. They differ in the form of care, the provision of medicines, and in the relationship with the patient.

In relation to the specialized visit:

“(...) We are very few doctors, , the internists help me... with the attention and the prescriptions"

"(...)they come and spend all night until at 5 am the statistics service opens its doors and at that time they start giving the appointments ...many times, they come one or two days, they do not get the appointments and then, they never come back." (the rheumatologist from the local hospital)

"...At any time, from 6 in the morning to 2 in the afternoon when they give you an appointment...yes, here you have to go and stand firmly and stay until dawn, if you want to make an appointment you have to dawn at the hospital!" (a nurse from a CAP)
"...No, here everything is bureaucracy for... when they are given an appointment all their studies have expired ...and they give up...because they get tired." (a nurse from a CAP)

In relation to treatment:

“...Many say that there are no medicines. But this is not true, actually. What happens is that it is necessary to go and pick them up." (the rheumatologist from the local hospital)

About the physician-patient nexus:

“...But people from... the communities are very difficult, though we find people from our race that are irresponsible. And even more and more each time. How can I tell you? Sometimes, they come with their families, so there is always somebody who looks after them, you see? And we also find patients from our race that are completely abandoned, or they are irresponsible." (an internist from the local hospital)

The perspective of community health workers (in the PACs and in the hospital) Both groups of community health workers express that the main barriers are communication and cultural barriers, as well as low capacity for attention towards native population; geographical barriers (distances) from the community to the hospital; and coordination between community different levels of attention. Their manner of interacting with the community is appropriate to biomedicine. However, they do not include the concept of intercultural health.

In relation to geographical barriers:

"... actually, when you are ill... and if it's dawn, you have to get up and go to the hospital, to the hospital that is far from here, an ambulance is the most important thing that is needed here at the health center to assist people." (a PAC community health worker)

In relation to treatment:

"...here in the health center we don't even have paracetamol!" (a PAC community health worker) "...follow up cannot be done because of the cost of medicines and of medical attention, we don't have specialized doctors, the only thing that we do is to make him seen by the woman doctor, but what do people do? They go out with a prescription to buy ibuprofen, because there is no ibuprofen!" (a PAC community health worker) 
They describe that the care of the physicians in the hospital is not adequate:

“...my brother, too, that is to say, he was hospitalized, a kidney problem has he, several times he ended up in hospital and there, we have to chase the doctor, chase the nurse guy for them to see him (...)" (a PAC community health worker)

\section{Enabling factors: contextual aspects of social relationships, community characteristics, and the healthcare system}

The perspective of local representatives of the qom community There is a distinction between biomedical and traditional medicine, which stimulates the search of medical attention. The community uses both kinds of medicine for the general management of the diseases. Another factor is the constant move from Chaco to Rosario, in the search of incomes, work, and health.

For the community, "older people are the structural pillars of the community":

“...today, healers, a few...because..there aren't many, already, our ancestors have already rested, and there aren't 'pioGonac', as it is said, but they take your money, only that, fake 'pioGonac' they are!" (a local representative of the qom community)

The perspective of healthcare professionals There is compromise from healthcare professionals with providing attention for the community, despite adversities such as labor strikes or precarious conditions that patients have. In the PACs, there is no delay in providing medical attention and, specially, in specialized attention. There is teamwork from both community health workers and PAC health professionals. At the hospital, the specialized consultation is provided by the only rheumatologist, who is supported by the team of internists. They highlight that the physician-patient relationship is essential:

“...You know, the doctor-patient relationship is an art, and even more with them, because they have such a characteristic way of being, that you don't know whether they are seeing you and they are understanding you, you don't know whether they are happy or sad... they are special. But once they recognize you as their general practitioner or as their reference, they always look for you, always." (an internist from the local hospital)
In the same way, the incorporation of the SASOI was essential for the improvement of the communication between health professionals, patients, and their families:

"They [SASOI]) are our connection mainly with the Toba [popular name for qom] community, the Tobas are the ones that we have here, especially when we need them to translate because there are some patients... the old ones [the speaker uses diminutive words to refer to the old people], who don't know how to speak Spanish... we have solved this, actually, this barrier, you see? [idiomatic barrier]." (an internist from the local hospital) "Hospital community health workers are very politicized... I, maybe, resolve with social workers. I have a better response from them. I have more professional secrecy... and they talk to them [patients] in a different way. Honestly, I have not had a good experience with the hospital community workers." (the rheumatologist from the local hospital)

The perspective of community health workers (in the PACs and in the hospital) Both groups of community health workers are technically competent. Many of them understand the language and a minority is bilingual. Human resources are available in both the PACs and the hospital. Their main role is to act as a link between the community and the healthcare system.

However, the lack of knowledge about traditional medicine is evident:

"...One [traditional doctor], but he's from the neighborhood... we have never connected with him, we can say... so far, yes, we have one. We have one, but...but, perhaps, they refrain from going. We don't know." (a PAC community health worker)

\section{Need factors}

The perspective of local representatives of the gom community The perspectives of local representatives of the qom community are to improve knowledge about healthcare system navigation, improve their relationship with the community health workers, and prioritize their culture.

The perspective of healthcare professionals The perspectives of healthcare professionals are to develop a culturally sensitive competence in healthcare professionals (general physicians, internists, and rheumatologists) to understand the qom culture and their traditional medicine and to develop biomedical competence for the early detection of rheumatic diseases and, among healthcare workers, a proposal to improve the local care circle and its interaction with that of Rosario. 
The healthcare professionals have developed different strategies to reduce the gaps in cultural competencies; however, these strategies are insufficient:

"I already have a way of making them understand, listen to me and understand. Because once they listen to and understand, in my case, they obey $100 \%$...I have a high response if the patient can understand and if the patient is self-sufficient."

"...I try to solve it; I have seen patients at siesta time for them not to make an appointment at night. Because it's dangerous. And the barbarities they have to listen to... and I'm really distressed for it..." (the rheumatologist from the local hospital)

"...communication by phone is a bit difficult because you have to simplify the words for everything that you want to inform them, so we also use a lot of non-verbal communication ... become like closer for them to understand." (an internist from the local hospital)

In relation to treatment:

"... I tell them: bring your pharmacy bag. Bring the medicine that you take sometimes, the medicine that you take every day, or the medicine that you used to take. You have to bring everything. And, then, what I do, when they take the medicines, I write how they have to take them on my instructions, and I make a kind of mini summary, with symbols. I also write the medicines from the cardiologist, or for the thyroids, if they have to take any ... I write everything on the sheet of paper. But, they have to bring me the medicines. I tell everything to my patients. 'Come with the pharmacy'. And I don't ask them to take any medicine if I don't know all the medicines that they are taking." (the rheumatologist from the local hospital)

“...people that are older, it's difficult, maybe they don't even know to speak Spanish, it's difficult to try to explain them how they need to take the different pills, you see?... Here we don't only have important problems with some pathologies, take rheumatology pathologies, for example, that you need two or three pills, but we also have Chagas [Disease], that produces heart failure, that makes patients leave the visit with seven or eight pills, you see? So, it becomes, maybe, more difficult and troublesome... many times they come with their families, so there is always somebody who gets involved, you see?" (the rheumatologist from the local hospital)

The perspective of community health workers (in the PACs and in the hospital) The perspectives of community health workers (in the PACs and in the hospital) are training of community health workers in the matters of communication, interpretation of medical indications, and introduction of the concept of intercultural health.

The different levels of analysis as well as the complexity of the healthcare system are shown in Fig. 2.

\section{Discussion}

This work is the first research conducted in the province of Chaco about the access to healthcare system of indigenous communities with musculoskeletal disorders and rheumatic disease from a qualitative approach. This study constitutes first phase of a culturally sensitive education program in the qom population living in Chaco, designed by GLADERPO.

One of the main findings resulting from this study is the different barriers. One of them is the communication between the community and the healthcare system. As regards this topic, the role of the PACs and community health workers is essential. On the one hand, the main goal of the PACs is to offer culturally competent care by providing multilingual interpreting services and addressing other cultural barriers to healthcare access faced by the communities they serve [17]. On the other hand, the link between the healthcare system and community is the community health workers, who "assist individuals and communities to adopt healthy behaviors" while helping "to conduct outreach" and "advocate for individuals and community health needs" $[18,19]$. When they are appropriately selected, trained, and supervised, the community health workers can be effective in improving population health and the access to healthcare system for minority groups. Loyola-Sanchez et al. [20] describe, in a qualitative study with indigenous individuals, a rheumatology model of care that improves the patient-provider communication, which is one of the pillars for a better quality of care. Another role of the community health workers in this community should be to become a bridge between traditional medicine and biomedicine, with the implementation of the concept of intercultural health. In this sense, Mignone et al. [21] describe different cases of intercultural health in Latin-American countries, prioritizing the need for community participation. This should be another relevant topic in the educational strategies. Another barrier is the cultural one; the community described prior experiences in the healthcare system and lack of understanding of their culture. The research team believes that the understanding of indigenous community culture should be an essential factor in educational strategies. In this sense, the Ottawa Charter for Health Promotion recommends the building of a healthy public policy, creating supportive environments, strengthening community action, developing personal skills, and reorienting health services [22]. Other authors describe cultural determinants of health that influence indigenous peoples' ability to access to the healthcare service to 


\section{Health System Bureaucracy}

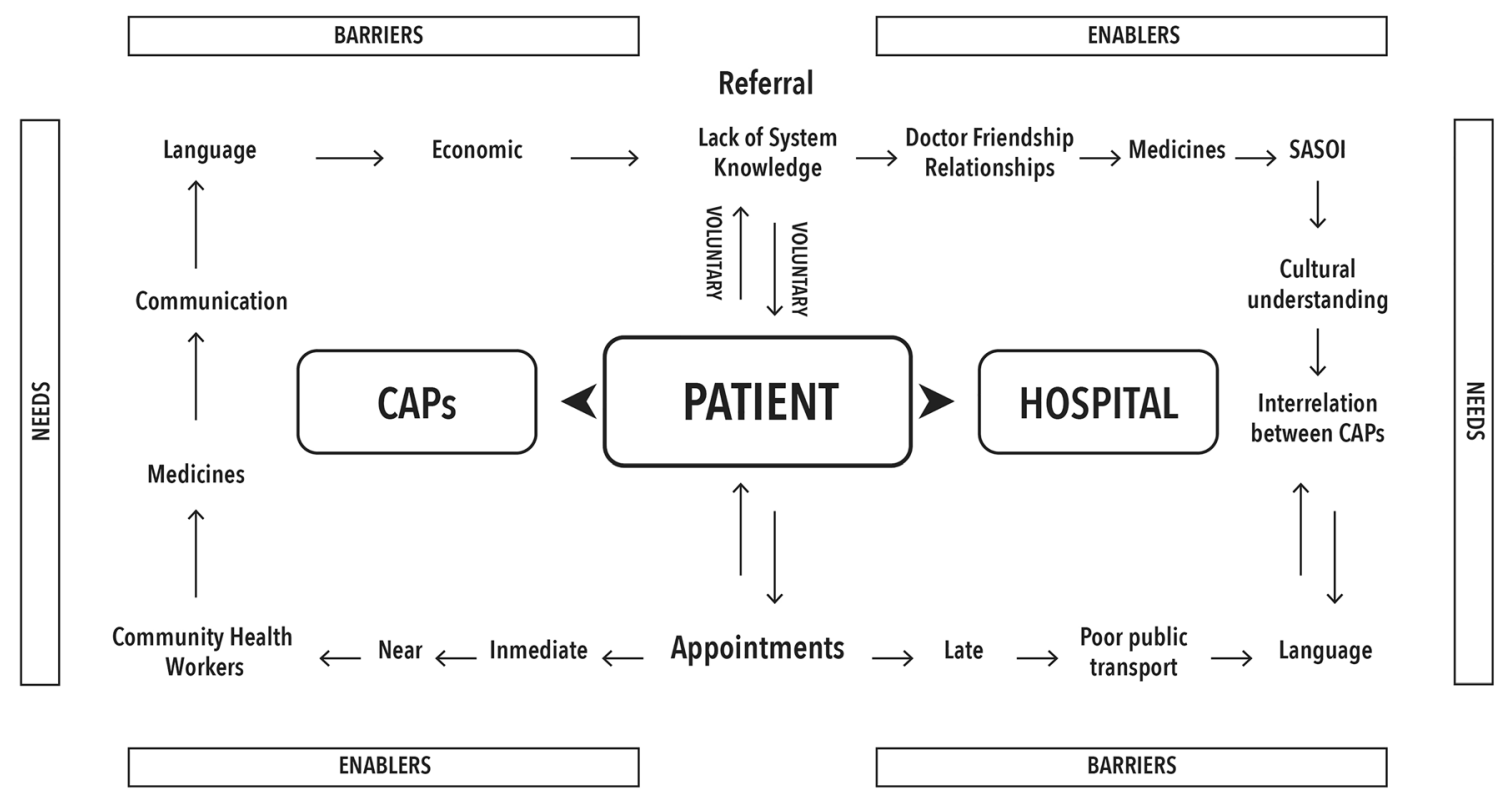

Fig. 2 Complexity in access to the health system

understand and take account of local beliefs and values when providing care [23-25].

Another finding to be highlighted is the "navigation" within the health system carried out by the qom community. This concept was first used to address the difficulties that low-income minority patients, in the United States, faced in receiving timely cancer screening and treatment [26]; in response to this problem, community health workers were trained to help patients [27, 28]. The model has been adapted since then to improve chronic disease care, and GLADERPO believes that it should be a priority in indigenous population.

Another concept for discussion is migration and health, which has been recognized as a health determinant, negatively impacting not only those who migrate but also sending, receiving, and "left behind" communities [29]. Health is an important reason for the community to move from their hometown to urban areas looking for better opportunities. However, as mentioned before, this pattern is associated with low adherence to treatment [6].

Within this context, it is also important to take into account the effect of the bureaucratization of the health system. Bureaucracy is a factor found in many large-scale organizations and in parts of most public sector organizations; it is a complex and dynamic aspect based on the use and implementation over time of rules and procedures into formal organizations [30]. In this article, it has been shown how bureaucracy has contributed to the fragmentation of the healthcare system between the PACs and the hospital, the unequal distribution of medication, as well as to the distribution of human resources to improve the connection between the different levels of care. These findings should be incorporated into educational strategies.

Finally, as regards health access models, the authors agree with the approach proposed by Penchansky R et al. [31] in the 1980s. This approach covers five dimensions (availability, accessibility, accommodation, affordability, and acceptability) which can be complemented with the World Health Organization (WHO) human rights-based proposal on healthcare accessibility in 2013 [32], where the dimensions of non-discrimination, accountability, and universality are added. A health accessibility approach based on human rights implies everybody has the right to control one's health and body without any interference and the right to a system of health protection that gives everyone an equal opportunity to enjoy the highest attainable level of health. Indigenous populations are considered to be within the vulnerable groups, with their rights to health accessibility violated.

The main limitations found were that this study was conducted in one specific group of individuals, which may not reflect the situation in other communities. However, the strengths were the qualitative approach, which helped with the understanding of a complex situation, and the fact that the same participants would be those who participate in the educational phase of this project. Through the model proposed by Andersen [7, 8], the conceptualization of need, enabling, and predisposing factors was described providing a framework on which to design future educational strategies.

The research team believes that they have the necessary data for the implementation of the next educational phase. 
The education proposal, with findings from this first phase, will be conducted in two modules. A module will be focused on developing a culturally sensitive competence of healthcare professionals to assist the qom community and the other module will be focused on the topic of healthcare system navigation for the qom community. In conclusion, the need to establish an interaction between the different levels of the local care system; to provide community health workers with an appropriate training to act as a link between the community and the healthcare system; and the incorporation of community representatives to improve access to healthcare system are the main challenges in the design and implementation of educational strategies.

Acknowledgments The authors are grateful to the International League of Associations for Rheumatology (ILAR) for the grant for this project; the Municipality of Presidencia Roque Saenz Peña for their support in accommodation and transfer of researches; the qom community, translators, and cultural facilitators; the heath professional workers of the PAC and the local hospital; local media for the dissemination of this project; and Alejandra Medina for the assistance with translation. Special acknowledgments are also given to Marta and Orlando support in accommodation.

\section{Compliance with ethical standards}

Disclosures None.

\section{Annex 1}

\section{Interview/observation guideline for health professionals}

General characteristics: gender, age, degree, how long the professional has been working in the community

\section{Reference:}

- How is the referral circuit, between the first level of attention and the hospital, for any chronic disease and, specially, for rheumatic diseases?

- How many professionals does the circuit involve? How long does it take to make the referral circuit between the first level of attention and the hospital? Is there any way of prioritizing patients for referrals and attention at upper levels such as a hospital or a specialist? Do patients attend the visits?

- For you, which ones are the main barriers and enablers in the link between the different attention levels? How would you describe your work experience with the community? Are you satisfied?

Accessibility:

- How do patients arrive? Do they come alone or with somebody?
- Barriers/difficulties when they want to communicate with the patients

- Do patients receive any economical support for their transport? If yes, how is the procedure?

- Do patients receive all the medicines? If yes, how is the procedure to get the medicines? If no, which medicines are not provided to the patients? Why not? Is there any medicine that needs a special authorization?

- Do patients receive any advice on their disease?

\section{Interview guideline for hospital community health workers}

General characteristics: gender, age, degree, how long the person has been working in the community. Do you know how to read and write? What has motivated you to do this kind of job?

Reference:

- ¿How do you know that somebody needs your help?

- ¿What circuit is followed with the patients? Please describe the professionals involved, the procedures that are performed

- Who is the link between the health center and the hospital??

Accessibility:

- How do you accompany the population? Appointments, access to medication, access to transport, studies

- What are the problems (barriers at all levels: personal, community, health system), that you know, that limit the attention? What do you think it would improve how to accompany patients so they can get an appropriate attention, as per health needs?

\section{Interview guideline for representatives of the community}

General information: ethnicity, gender, age, occupation. Do you know how to read and write?

Reference:

- Please describe the way you follow when you, or any member of your family, or a friend, have a health problem, and how your experience has been at the different attention levels. Do you go to the doctor/health center? When? Does the same doctor always see you? Have you ever been to the hospital? If yes, When? Do you have to make an appointment to see a doctor? How do you make an appointment? 
Accessibility (quality of attention):

- How did you come to the hospital/health center?

- Who came to the hospital/health center with you? Who gave you the appointment to get to the hospital/health center? Do you feel the doctor understands you when you tell him/her your problems?

- Do you understand the doctor's instructions?

- Do you feel comfortable with the attention received?

- Do you feel that it takes too much time to get to your visit to a doctor at the hospital/health center?

\section{Belief System:}

- Tell us, when you see your community healer, do you see him/her during the time you see your doctor, or you see him/her before or after?

- How do you take the decision on who you visit first?

- What experience have you had with both attention systems: biomedical system and traditional system?

\section{References}

1. Brooks PM (2006) The burden of musculoskeletal disease-a global perspective. Clin Rheumatol 25(6):778-781

2. Pelaez-Ballestas I, Pons-Estel BA, Burgos-Vargas R (2016) Epidemiology of rheumatic diseases in indigenous populations in Latin-Americans. Clin Rheumatol 35(Suppl 1):1-3

3. Ferucci ED, Templin DW, Lanier AP (2005) Rheumatoid arthritis in American Indians and Alaska natives: a review of the literature. Semin Arthritis Rheum 34(4):662-667

4. Hurd K, Barnabe C (2017) Systematic review of rheumatic disease phenotypes and outcomes in the Indigenous populations of Canada, the USA, Australia and New Zealand. Rheumatol Int 37(4):503-521

5. Quintana R, Silvestre AM, Goni M, Garcia V, Mathern N, Jorfen M et al (2016) Prevalence of musculoskeletal disorders and rheumatic diseases in the indigenous qom population of Rosario, Argentina. Clin Rheumatol 35(Suppl 1):5-14

6. Quintana R, Goni M, Mathern N, Jorfen M, Conti S, Nieto R et al (2018) Rheumatoid arthritis in the indigenous qom population of Rosario, Argentina: aggressive and disabling disease with inadequate adherence to treatment in a community-based cohort study. Clin Rheumatol 37(9):2323-2330

7. Andersen RM (1995) Revisiting the behavioral model and access to medical care: does it matter? J Health Soc Behav 36(1):1-10

8. Hendrickx D, Amgarth-Duff I, Bowen AC, Carapetis JR, Chibawe R, Samson M, et al. (2020) Barriers and enablers of health service utilisation for childhood skin infections in remote aboriginal communities of Western Australia. Int J Environ Res Public Health. 17(3)

9. Censo Nacional de población, hogares y viviendas 2010 . [Consultado en enero 2018]. Disponible: www.indec.gov.ar.

10. Encuesta Complementaria de Pueblos Indígenas; 2004-2005 [Consultado en Enero 2018]. Disponible: https://www.indec.gov. $\mathrm{ar} / \mathrm{micro}$ sitios/webcenso/ECPI/index ecpi.asp? ga $=2$. $18874148 \overline{6} .733888255 .1516285889-933371335.1516285889$.
11. Cuyul A. Salud indígena y políticas de salud intercultural en la provincia de Chaco, Argentina. 2012:https://archivo.argentina. indymedia.org/uploads/2012/04/salud_indigena_y_politicas_ interculturales_a._cuyul.pdf.

12. Nowell L, Norris JM, Mrklas K, White DE (2017) Mixed methods systematic review exploring mentorship outcomes in nursing academia. J Adv Nurs 73(3):527-544

13. Nowell L, Norris JM, Mrklas K, White DE (2017) A literature review of mentorship programs in academic nursing. J Prof Nurs 33(5):334-344

14. Carter N, Bryant-Lukosius D, DiCenso A, Blythe J, Neville AJ (2014) The use of triangulation in qualitative research. Oncol Nurs Forum 41(5):545-547

15. Tong A, Sainsbury P, Craig J (2007) Consolidated criteria for reporting qualitative research (COREQ): a 32-item checklist for interviews and focus groups. Int J Qual Health Care 19(6):349-357

16. Fitzpatrick EF, Martiniuk AL, D'Antoine H, Oscar J, Carter M, Elliott EJ (2016) Seeking consent for research with indigenous communities: a systematic review. BMC Med Ethics 17(1):65

17. Saloner B, Wilk AS, Levin J (2020) Community health centers and access to care among underserved populations: a synthesis review. Med Care Res Rev 77(1):3-18

18. Perry HB, Zulliger R, Rogers MM (2014) Community health workers in low-, middle-, and high-income countries: an overview of their history, recent evolution, and current effectiveness. Annu Rev Public Health 35:399-421

19. Fleckman JM, Dal Corso M, Ramirez S, Begalieva M, Johnson CC (2015) Intercultural competency in public health: a call for action to incorporate training into public health education. Front Public Health 3:210

20. Lin CY, Loyola-Sanchez A, Hurd K, Ferucci ED, Crane L, Healy B, Barnabe C (2019) Characterization of indigenous community engagement in arthritis studies conducted in Canada, United States of America, Australia and New Zealand. Semin Arthritis Rheum 49(1):145-155

21. Mignone J, Bartlett J, O'Neil J, Orchard T (2007) Best practices in intercultural health: five case studies in Latin America. J Ethnobiol Ethnomed 3:31

22. World Health Organization: The Ottawa charter for health promotion.

23. Davy C, Harfield S, McArthur A, Munn Z, Brown A (2016) Access to primary health care services for indigenous peoples: a framework synthesis. Int J Equity Health 15(1):163

24. Gibson O, Lisy K, Davy C, Aromataris E, Kite E, Lockwood C, Riitano D, McBride K, Brown A (2015) Enablers and barriers to the implementation of primary health care interventions for Indigenous people with chronic diseases: a systematic review. Implement Sci 10:71

25. Levesque JF, Harris MF, Russell G (2013) Patient-centred access to health care: conceptualising access at the interface of health systems and populations. Int $\mathrm{J}$ Equity Health 12:18

26. Natale-Pereira A, Enard KR, Nevarez L, Jones LA (2011) The role of patient navigators in eliminating health disparities. Cancer. 117(15 Suppl):3543-3552

27. Austad K, Chary A, Martinez B, Juarez M, Martin YJ, Ixen EC, Rohloff P (2017) Obstetric care navigation: a new approach to promote respectful maternity care and overcome barriers to safe motherhood. Reprod Health 14(1):148

28. Chary A, Flood D, Austad K, Colom M, Hawkins J, Cnop K, Martinez B, Lopez W, Rohloff P (2018) Accompanying indigenous Maya patients with complex medical needs: a patient navigation system in rural Guatemala. Healthc (Amst) 6(2):144-149

29. Wickramage K, Vearey J, Zwi AB, Robinson C, Knipper M (2018) Migration and health: a global public health research priority. BMC Public Health 18(1):987 
30. Coccia M (2009) Bureaucratization in public research institutions. Minerva. 47(1):31-50

31. Penchansky R, Thomas JW (1981) The concept of access: definition and relationship to consumer satisfaction. Med Care 19(2): $127-140$
32. WHOTrth. [Available from: https://www.who.int/es/news-room/ fact-sheets/detail/human-rights-and-health.

Publisher's note Springer Nature remains neutral with regard to jurisdictional claims in published maps and institutional affiliations. 